\title{
Editorial: Technological and Fundamental Advances in Production, Storage and Utilization of Fuels
}

\author{
Maurizio Troiano ${ }^{1}$, Alfonso Chinnici ${ }^{2 *}$, Selvan Bellan ${ }^{3}$ and Graham J Nathan ${ }^{2}$ \\ ${ }^{1}$ Department of Chemical, Materials and Industrial Production Engineering, University of Naples Federico II, Naples, Italy, ${ }^{2}$ Centre \\ for Energy Technology, School of Mechanical Engineering, The University of Adelaide, Adelaide, SA, Australia, ${ }^{3}$ Centre for \\ Transdisciplinary Research, Institute of Science and Technology, Niigata University, Niigata, Japan
}

Keywords: hydrogen, ammonia, chemical reactors, solar fuels and chemicals, catalysis, combustion science, thermo-chemistry

\section{Editorial on the Research Topic}

Technological and Fundamental Advances in Production, Storage and Utilization of Solar Fuels

\section{OPEN ACCESS}

Edited and reviewed by: Ellen B. Stechel,

Arizona State University, United States

*Correspondence:

Alfonso Chinnici

alfonso.chinnici@adelaide.edu.au

Specialty section:

This article was submitted to

Process and Energy Systems

Engineering,

a section of the journal

Frontiers in Energy Research

Received: 07 December 2021

Accepted: 28 January 2022

Published: 23 February 2022

Citation:

Troiano M, Chinnici A, Bellan S and Nathan GJ (2022) Editorial:

Technological and Fundamental Advances in Production, Storage and

Utilization of Fuels.

Front. Energy Res. 10:830772.

doi: 10.3389/fenrg.2022.830772
The global focus on decarbonisation is driving demand for low carbon energy solutions and innovation in clean technologies for fuel production, storage and utilisation. Solar fuels represent a versatile and attractive method to store sunlight, which is by far the most abundant carbon-neutral energy resource on Earth, although it is intermittent in nature. These fuels (e.g., hydrogen, syngas or liquid fuels) can play different roles in a sustainable, global energy transformation scenario, including fossil fuel upgrade, heat/power generation for industrial and domestic uses, transport, and as a clean feedstock to produce cleaner chemicals (Nathan et al., 2017). A rapid deployment and adaptation of these fuels in the energy market requires technologies that are efficient and that can produce large amounts of chemical fuels directly from sunlight in a robust, clean and cost-effective way (Steinfeld, 2005), achieving the same economies of scale obtained in established processes. Technological advancements in both fuel storage and utilisation are also required to achieve a fully sustainable and clean supply chain.

The objective of this Research Topic is to highlight and discuss the latest fundamental and technological advancements in the production, storage and utilisation of solar fuels to provide both cost-effective $\mathrm{CO}_{2}$ mitigation and low-cost energy generation.

In this Research Topic the editorial team welcomed Original Research on several specific themes related to solar fuels, including recent advancements in the solar thermochemical conversion of biomass for both fuel and chemicals production, novel solar thermochemical receivers-reactors for catalytic hydrogen production, water and carbon dioxide splitting via catalysts for fuel production, and the utilisation of solar fuels (ammonia and hydrogen-enriched fuels) in flameless combustion processes. Furthermore, this research topic welcomed a Review article on the applications of solardriven fluidised bed processes.

Bellouard et al. investigate the combined solar gasification of biomass and iron oxide reduction for syngas and iron production. Thermodynamic equilibrium calculations are reported, together with experiments carried out in an induction furnace at high heating rates, being representative of concentrating solar installations. Results suggest that solar gasification over iron oxide is a viable option to produce green iron in a sustainable metallurgical process and/or additional hydrogen via chemical looping in a steam-iron process.

Yang et al. propose a novel solar thermochemical receiver-reactor array concept for hydrogen production via ceria redox cycling, and numerically study its performance. Results indicate that the solar-to-fuel efficiency is highly sensitive to the concentration ratio and the gas-phase heat recovery effectiveness at high reduction temperature and low relative oxygen partial pressure conditions. 
Luciani et al. investigate the catalytic properties of $\mathrm{K}^{+}$and $\mathrm{Cu}^{2}$ ${ }^{+} / \mathrm{Fe}^{3+} \mathrm{co}$-doped ceria-zirconia $(\mathrm{CeZr})$ toward water and carbon dioxide co-splitting. Thermogravimetric analysis indicates that the addition of potassium allows faster oxidation kinetics, with a peak in hydrogen production at relatively low temperatures. The $\mathrm{K}-\mathrm{Fe}-\mathrm{CeZr}$ sample shows a second oxidation phenomenon at a higher temperature, which can be related to the oxidation of bulk ceria-zirconia. Three regimes are identified by comparing the calculated surface reaction rates at different temperatures, and the appropriate conditions for tuning hydrogen/carbon monoxide selectivity are provided.

Tou et al. examine the concept of a thermochemical membrane reactor to split $\mathrm{CO}_{2}$ and produce solar fuels for three configurations: a single oxygen-permeable membrane, a single hydrogen-permeable membrane, and a dual oxygenpermeable, hydrogen-permeable membrane configuration. Calculation results indicate that solar-to-fuel energy efficiency realistically attainable with a dual-membrane configuration is the highest among the investigated configurations. Critical comments are reported regarding the optimum operating conditions based on physical feasibility in terms of total pressure, temperature and suitable ceramic materials.

Amaduzzi et al. investigate operational strategies of flameless combustion processes fed by hydrogen-enriched (solar) fuels. The effects of parameters such as gas composition, injector geometry and dilution species are numerically investigated to assess whether flameless conditions are achievable for a number of different operating conditions. Results indicate that fuel dilution with either $\mathrm{CO}_{2}$ or $\mathrm{H}_{2} \mathrm{O}$ leads to an overall smoothing of the temperature gradients in the combustion chamber, along with decreased $\mathrm{OH}$ emissions. Fuel inlet length and equivalence ratio may lead to flameless conditions in the combustion chamber for a broader range of fuel mixtures.

Ferrarotti et al. investigate the behavior of ammonia/ hydrogen $\left(\mathrm{NH}_{3} / \mathrm{H}_{2}\right)$ blends under flameless conditions. A first-of-a-kind experimental study is carried out to assess

\section{REFERENCES}

Nathan, G. J., Dally, B. B., Alwahabi, Z. T., Van Eyk, P. J., Jafarian, M., and Ashman, P. J. (2017). Research Challenges in Combustion and Gasification Arising from Emerging Technologies Employing Directly Irradiated Concentrating Solar thermal Radiation. Proc. Combust. Inst. 36, 2055-2074. doi:10.1016/j.proci.2016.07.044

Steinfeld, A. (2005). Solar Thermochemical Production of Hydrogen-Aa Review. Solar Energy 78, 603-615. doi:10.1016/j.solener.2003.12.012

Conflict of Interest: The authors declare that the research was conducted in the absence of any commercial or financial relationships that could be construed as a potential conflict of interest. fuel flexibility for different $\mathrm{NH}_{3} / \mathrm{H}_{2}$ blends in a flameless burner. Results indicate that a significant portion of the discrepancy between the pollutant emissions from simulations and experimental observations can be associated to uncertainties in recent kinetic mechanisms for $\mathrm{NH}_{3} / \mathrm{H}_{2}$ combustion. This work indicates the need to improve existing $\mathrm{NH}_{3} / \mathrm{H}_{2}$ models, especially in diluted conditions.

Sorrentino et al. analyse the steady oxidative structures occurring when ammonia is used as a fuel in diffusion ignition processes. A characterisation has been carried out in a wide range of feeding parameters under Moderate or Intense Low-oxygen Dilution (MILD) combustion conditions. Maps of behavior are obtained based on the oxidative structure peculiarities recognised from temperature and heat release profiles.

Tregambi et al. review the current and perspective applications of fluidised beds to collection, storage and exploitation of solar radiation. Novel designs of fluidised bed solar receivers-reactors are reported and critically discussed. The field of applications of solar-driven fluidised bed processes, from energy conversion with thermal energy storage, to solids looping for thermochemical energy storage, production of fuels, chemicals and materials, is explored with an eye at past and current developments, and an outlook of future perspectives.

In conclusion, the research topic provides an overview of key aspects and existing challenges in solar fuels production and utilisation, highlighting the current research efforts and the opportunities ahead. The interesting outcomes from this collection encourage future research efforts to fast-track the deployment and adaptation of solar fuels in the global energy market.

\section{AUTHOR CONTRIBUTIONS}

All authors listed have made a substantial, direct, and intellectual contribution to the work and approved it for publication.

Publisher's Note: All claims expressed in this article are solely those of the authors and do not necessarily represent those of their affiliated organizations, or those of the publisher, the editors and the reviewers. Any product that may be evaluated in this article, or claim that may be made by its manufacturer, is not guaranteed or endorsed by the publisher.

Copyright (c) 2022 Troiano, Chinnici, Bellan and Nathan. This is an open-access article distributed under the terms of the Creative Commons Attribution License (CC $B Y)$. The use, distribution or reproduction in other forums is permitted, provided the original author(s) and the copyright owner(s) are credited and that the original publication in this journal is cited, in accordance with accepted academic practice. No use, distribution or reproduction is permitted which does not comply with these terms. 